\title{
Essential oil from Korean Chamaecyparis obtusa leaf ameliorates respiratory activity in Sprague-Dawley rats and exhibits protection from NF-kB-induced inflammation in WI38 fibroblast cells
}

\author{
SUCHISMITA RAHA ${ }^{1}$, SEONG MIN KIM ${ }^{1}$, HO JEONG LEE ${ }^{1}$, SANG JOON LEE ${ }^{2}$, \\ JEONG DOO HEO $^{2}$, VENU VENKATARAME GOWDA SARALAMMA ${ }^{1}$, \\ SANG EUN HA ${ }^{1}$, EUN HEE KIM ${ }^{3}$, SUNG PHIL MUN ${ }^{4}$ and GON SUP KIM ${ }^{1}$

\begin{abstract}
${ }^{1}$ Research Institute of Life Science, College of Veterinary Medicine, Gyeongsang National University; ${ }^{2}$ Gyeongnam Department of Environment Toxicology and Chemistry, Toxicology Screening Research Center, Korea Institute of Toxicology, Jinju, Gyeongsang 52828; ${ }^{3}$ Department of Nursing Science, International University of Korea, Jinju, Gyeongsang 52833; ${ }^{4}$ Department of Wood Science and Technology, Chonbuk National University, Jeonju, Jeollabuk 54896, Republic of Korea
\end{abstract}

Received June 9, 2018; Accepted October 25, 2018

DOI: $10.3892 /$ ijmm.2018.3966

\begin{abstract}
To date, Korean hinoki cypress (Chamaecyparis obtusa), has been widely used for household and commercial purposes. Although the medicinal efficacy of hinoki cypress essential oil has been observed, that of the essential oil-derived terpenes, which exhibit a mechanism that acts against lung inflammation, remains to be fully elucidated. The present study investigated the anti-inflammatory effect of hinoki cypress leaf extracted essential oil on lipopolysaccharide (LPS)-stimulated WI38 fibroblast cells by inhibiting the nuclear factor $\kappa$-light-chain-enhancer of activated $B$ cells $(N F-\kappa B)$ pathway, which exhibited lung tissue protection through the olfactory administration of essential oil in Sprague-Dawley rats. GC/MS analysis derived 24 terpenes from the essential oil. The morphological observations revealed that, upon LPS stimulation of WI38 fibroblast cells, inflammation was induced, whereas the condition of the cells reverted to normal in the essential oil extract pre-treated group. The results
\end{abstract}

Correspondence to: Professor Gon Sup Kim, Research Institute of Life Science, College of Veterinary Medicine, Gyeongsang National University, 501 Jinju-daero, Jinju, Gyeongsang 52828, Republic of Korea

E-mail: gonskim@gnu.ac.kr

Professor Sung Phil Mun, Department of Wood Science and Technology, Chonbuk National University, 567 Baekje-daero, Jeonju, Jeollabuk 54896, Republic of Korea

E-mail: msp@jbnu.ac.kr

Key words: Chamaecyparis obtusa, gas chromatography/mass spectrometry, essential oil, terpene, lipopolysaccharides, WI38 fibroblast cells, inflammation of western blot analysis revealed the inhibition of inducible nitric oxide synthase, activation of cyclooxygnase- 2 , and the degradation of cytosolic p65 and inhibitor of NF- $\kappa \mathrm{B}-\alpha$ in the LPS-stimulated group. Additionally, confocal imaging of nuclei revealed the translocation of phosphorylated p65, which was recovered in the cytosol in the phytoncide essential oil pre-treated group. Histopathological observation revealed that the alveolar capacity was enhanced in the essential oil olfactory administered rat group, compared with that in the normal rat group. These findings suggest that terpenes in essential oil from the Chamaecyparis obtusa leaf have therapeutic potential against respiratory inflammation-related disease.

\section{Introduction}

Respiratory diseases have been considered to contribute to the global burden of disease in the last two decades. Lung diseases that have attributed to global mortality rates include lower respiratory infection, chronic obstructive pulmonary disease (COPD), lung cancer, tuberculosis and pneumonia infection. According to the World Health Organization, by 2030 , morbidity rates due to respiratory diseases may increase based on the rise of air pollution, chronic respiratory problems and respiratory infections associated with all health-related issues worldwide. Despite an alarming increase in this issue worldwide, the complexity of chronic airway or lung inflammation remains a serious limitation in establishing a clear understanding of such diseases (1).

Lung inflammation is usually caused by pathogens or by exposure to toxins, pollutants, irritants, and allergens. Acute lung inflammation includes pneumonia and acute respiratory distress syndrome; whereas chronic inflammation includes asthma and COPD (2). In laboratory animals, lung inflammation is detected by the presence of inflammatory markers, including immune cells and cytokines, in the 
bronchoalveolar lavage fluid of sacrificed animals (3). The respiratory system comes into direct contact with a low level of lipopolysaccharide (LPS) present as a contaminant in airborne particles. Exposure to LPS results in several characteristics of lung inflammation, including the upregulation of myosin light chain phosphorylation and airway epithelial barrier permeability with increasing levels of albumin, myeloperoxidase activity and infiltration of neutrophils (4), and can cause acute lung injury due to bilateral alveolar infiltration, lung edema and respiratory failure. Therefore, a better understanding of the pathogens or stress associated with lung inflammation and potential targets for treatment which can maintain lung homeostasis, is always dependent on the characteristics of cells or tissue involvement.

Fibroblasts, which are traditionally recognized as quiescent cells responsible for extracellular matrix production, are known to be actively involved the immune system (5). In chronic lung diseases, the number and phenotypes of fibroblasts cells are altered as they are able to modulate the immune response, however, any impairment in immune regulation involves the disruption of controlling activity and leads to inflammation and damage (6). Previous studies have implicated fibroblasts as cells which contribute to disease persistence and define anatomical location. Therefore, fibroblasts are an attractive therapeutic target as they assist in orchestrating the infiltration of inflammatory agents (7). Essential oils, including hinoki cypress leaf oil, have long been used as commercialized products, including fragrances (8), air purifiers and human-safe insect repellent (9).

The physiological activities of phytoncide extract include anti-oxidant, antimicrobial, insecticidal and antifungal properties (10). It can also be used as an alternative antibiotic in weaning pigs via dietary supplementation (11). The forest bathing of phytoncide volatile oil has shown to increase natural killer (NK) cells (12), decrease stress hormones (13) and even induce physiological relaxation through olfactory stimulation in humansin aromatherapy (8). Monoterpenes of plant essential oils exert several antitumor activities (14), whereas monoterpene 1.8-cineole of Eucalyptus globulus oil (15) and tymol, carvacrol, $p$-Cymene from Lippia sidoides leaves $(16,17)$ have shown inflammatory activities in vivo. Chamaecyparis obtusa (C. obtusa) essential oil extract has shown to have an anti-inflammatory effect against paw edema and peritonitis (18). However, cypress leaf essential oil-derived terpenes have not been examined in vitro or in vivo for their potential in attenuating inflammatory mediators in lung inflammation.

Therefore, the present study investigated the anti-inflammatory effect of hinoki cypress leaf extracted essential oil in LPS-stimulated WI38 fibroblast cells by inhibiting the nuclear factor $\kappa$-light-chain-enhancer of activated $B$ cells $(N F-\kappa B)$ pathway and its ability to enhance the lung tissue capacity of Sprague-Dawley rats.

\section{Materials and methods}

Plant material and preparation of leaf essential oil. Shredded and frozen hinoki (C. obtusa) leaves $(<1 \mathrm{~cm}$ in length) were kindly provided by Napoli Co., Ltd. (Tonyoung, South Korea) in May 2017. The leaves ( 600 g) were placed in a 21 round-bottom flask with 1.21 de-ionized water and a Clevenger-type apparatus was then attached to collect the essential oil. Following $11 \mathrm{~h}$ of steam distillation, the volume of essential oil was measured, and the oil was then transferred to a $15 \mathrm{ml}$ vial and weighed. The oil yield was calculated according to the following equation: Essential oil $(\mathrm{w} / \mathrm{w} \%)=$ (weight of essential oil/weight of hinoki leaves) $\mathrm{x} 100$.

Phytoncide essential oil with $100 \%$ mixture and $100 \%$ purity at a concentration of $1 \mathrm{gm} / \mathrm{ml}(1 \mathrm{ml})$ stock was obtained from Professor Sung Phil Mun of Chonbuk National University (Jeonju, South Korea).

Essential oil analysis using GC/MS. A GC/MS QP 2010 (Shimadzu Corporation, Kyoto, Japan) equipped with a CBP5 fused silica capillary column ( $30 \mathrm{~m}$ x $0.25 \mathrm{~mm}$ i.d., $0.25 \mu \mathrm{m}$ film thickness; Shimadzu Corporation) was used for the analysis of the leaf essential oil constituents. The oven temperature was maintained at $40^{\circ} \mathrm{C}$ for $5 \mathrm{~min}$, and then increased by $3^{\circ} \mathrm{C} / \mathrm{min}$ to $220^{\circ} \mathrm{C}$ and increased again by $10^{\circ} \mathrm{C} / \mathrm{min}$ to $280^{\circ} \mathrm{C}$ and held for $5 \mathrm{~min}$. The injector temperature was $300^{\circ} \mathrm{C}$ and the interface temperature was $230^{\circ} \mathrm{C}$ with the EI mode at $70 \mathrm{eV}$. He gas was used as the carrier gas at a flow rate of $1 \mathrm{ml} / \mathrm{min}$ and the split ratio was 1:30. The MS scan range was $\mathrm{m} / \mathrm{z}$ 35-500. Identification of the oil components was based on comparisons of relative retention indices calculated from a mixture of aliphatic hydrocarbons ranging between $\mathrm{C} 7$ and $\mathrm{C} 30$ and from the NIST11 database (https://www.nist.gov).

Chemical and reagents. LPS and 3-(4,5-dimethylthiazol2-yl)-2,5-diphenyltetrazolium bromide (MTT) were purchased from Sigma-Aldrich; Merck KGaA (Darmstadt, Germany). $\alpha$-minimum essential medium (MEM) was purchased from Lonza Group, Ltd. (Walkersville, MD, USA). Fetal bovine serum (FBS) and penicillin/streptomycin (P/S) antibiotics were obtained from Gibco; Thermo Fisher Scientific, Inc. (Waltham, MA, USA). The materials and chemicals used for electrophoresis were obtained from Bio-Rad Laboratories, Inc. (Hercules, CA, USA). The primary antibodies against rabbit inducible nitric oxide synthase (iNOS; cat. no. 13120), p65 (cat no. 8242S), phosphorylated (p)-p65 (cat. no. 3033S),

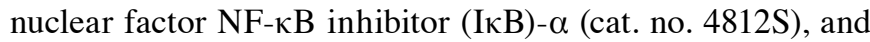
anti-rabbit Alexa fluor 594 (cat. no. 8889S) conjugate were purchased from Cell Signaling Technology, Inc. (Beverly, MA, USA). Cyclooxygenase-2 (COX-2; cat. no. SC-1745) goat polyclonal and donkey anti-goat (cat. no. SC-2354) IgG HRP conjugate secondary antibodies were purchased from Santa Cruz Biotechnology, Inc. (Santa Cruz, CA, USA). Anti-rabbit (cat. no. ADI-SAB-300) IgG horseradish conjugate secondary antibody was obtained from Enzo Life Sciences, Inc. (Minneapolis, MN, USA). Goat anti-mouse (cat. no. A90-116P) IgG HRP conjugate secondary antibody was purchased from Bethyl Laboratories, Inc. $\beta$-actin (cat. no. MAB1501) antibody was purchased from EMD Millipore (Billerica, MA, USA). All chemicals used were of the highest grade commercially available.

Experimental animals. Male Sprague-Dawley rats (6-week-old, 150 g; Samtaco, Osan, Korea) were used for the in vivo experiments. The experiment was performed following the standard animal science guidelines reviewed and approved 
by the Ethics Committee of Gyeongnam Biological Resource Research Center (Gyeongnam, Korea). Prior to use, the rats were acclimatized for 3 days in a normal room ambience (room temperature: $20-24^{\circ} \mathrm{C}$; relative humidity: $40-70 \% ; 12 \mathrm{~h}$ light/dark cycle), with free access to standard rodent chow and softened tap water. Each group consisted of three rats and comprised the control and phytoncide essential oil-inhaled groups. Phytoncide essential oil $\left(100 \mathrm{~kg} / \mathrm{cm}^{3}\right.$ maximum, as per the recommendation of Chunbuk National University) was administered through an oxygen channel into the cage for 4 weeks. After 4 weeks, all mice were anesthetized with ether solution and sacrificed by cervical dislocation.

Hematoxylin and eosin staining. The xenograft lung tissues were fixed with $4 \%$ paraformaldehyde overnight. The tissues were then embedded with paraffin. The embedded paraffin was removed from the samples with $100 \%$ xylazine and dehydrated with different concentrations of ethanol $(95,90,80$, and $70 \%$ ). The tissue samples were stained with hematoxylin for 3 min and placed on $0.3 \%$ acid alcohol for differentiation. The samples were rinsed with Scott's tap water prior to exposure to eosin solution for $3 \mathrm{~min}$. Following staining with hematoxylin and eosin, tissue samples were dried and protected with a cover slide. The samples were then observed under a light microscope.

Cell culture. The WI38 human embryonic fibroblast, lung tissue-derived cell line was obtained from the Korean Cell Line Bank (Seoul, Korea). The WI38 fibroblast cells were maintained in $\alpha$-MEM media supplemented with $20 \%$ heat-inactivated $\mathrm{FBS}$ and $1 \% \mathrm{P} / \mathrm{S}$ at $37^{\circ} \mathrm{C}$ in a $5 \% \mathrm{CO}_{2}$ incubator. The LPS was dissolved in $1 \mathrm{X}$ PBS.

Cell viability. To assess WI38 cell compatibility, the cells were seeded at a density of $6 \times 10^{5}$ cells per well in 24 -well plates and treated with various concentrations of phytoncide essential oil $(1-50 \mu \mathrm{g} / \mathrm{ml})$ and LPS $(1-10 \mu \mathrm{g} / \mathrm{ml})$ followed by incubated at $37^{\circ} \mathrm{C}$ for $24 \mathrm{~h}$. An MTT assay was performed to evaluate cell viability. Following treatment, MTT solution $(5 \mathrm{mg} / \mathrm{ml}$ in 1X PBS) was added followed by incubation for $3 \mathrm{~h}$ at $37^{\circ} \mathrm{C}$ in the dark. The formazan crystals formed were solubilized by incubating cells with $500 \mu 1$ of DMSO. Cell absorbance was read by an enzyme-linked immunosorbent assay (ELISA) plate reader (BioTek Instruments, Inc., Winooski, VT, USA) at $540 \mathrm{~nm}$. Cell proliferation was quantified as a percentage compared with the positive control and negative control group accordingly, which was set at $100 \%$.

Western blot analysis. Briefly, the WI38 cells, which had been pre-treated with $1-10 \mu \mathrm{g} / \mathrm{ml}$ phytoncide essential oil for $1 \mathrm{~h}$ prior to $5 \mu \mathrm{g} / \mathrm{ml}$ of LPS for $24 \mathrm{~h}$, were lysed overnight with RIPA lysis buffer containing phosphatase inhibitor cocktail, protease inhibitor and EDTA (Thermo Fisher Scientific, Inc.). The extracted proteins were then centrifuged at $21,000 \mathrm{x} \mathrm{g}$ for $30 \mathrm{~min}$ at $4^{\circ} \mathrm{C}$ to remove debris. The proteins were resolved using 10-12\% SDS-PAGE and subsequently transferred onto a polyvinylidene difluoridemembrane (Immunobilon-P, $0.45 \mathrm{~mm}$; EMD Millipore) using the TE 77 Semi-Dry transfer unit (GE Healthcare Life Sciences, Chalfont, UK). The membranes were blocked with 5\% non-fat milk in Tris-buffered saline containing $1 \%$ Tween-20 (TBS-T, pH 7.4) or $1 \mathrm{X}$ phospho blocking solution (TransLab Biosciences, Daejeon, Korea) at room temperature for $1 \mathrm{~h}$. The blots were probed with a 1: 1,000 dilutions for the primary antibodies viz., iNOS, p65, p-p65, IкB- $\alpha$ and 1:250 for COX-2 at $4^{\circ} \mathrm{C}$ for overnight. The membranes were washed five times with TBS-T, and were then incubated with diluted enzyme-linked secondary antibodies at 1:1,000 for anti-rabbit, 1:2,000 for anti-goat and 1:3,000 for anti-mouse at room temperature for $3 \mathrm{~h}$. The membranes were then visualized using an enhanced chemiluminescence kit and western blotting detection reagents (GE Healthcare Life Sciences). ImageJ software v.1.51u (National Institutes of Health, Bethesda, MD, USA) was used to quantify each protein band, followed by densitometry reading performed following normalization with the expression of $\beta$-actin.

Confocal imaging. Briefly, the cells were seeded on $15 \mathrm{~mm}$ microscope cover glass (Paul Marienfeld GmbH \& Co., KG, Lauda-Königshofen, Germany) at a density of $5 \times 10^{6}$ cells/well in 12-well plates and grown overnight, followed by pre-treatment with essential oil and LPS stimulation for $24 \mathrm{~h}$. For antibody labeling, the cells were first fixed with $37 \%$ formaldehyde and $95 \%$ ethanol (1:4) for $15 \mathrm{~min}$ at room temperature, followed by washing with $1 \mathrm{X}$ PBS three times ( $5 \mathrm{~min} / \mathrm{wash}$ ) and blocking with 1\% BSA (Bioshop, Canada, Inc., Burlington, ON, Canada)/1X PBS for $1 \mathrm{~h}$ at room temperature. The cells were probed overnight with a 1:100 ratio of diluted antibody (p-p65) at $4^{\circ} \mathrm{C}$. Following washing with $1 \mathrm{X}$ PBS four times (7-10 $\mathrm{min} / \mathrm{wash}$ ), the cells were blocked with 1:250 diluted anti-rabbit Alexa fluor 594 conjugate Red at room temperature for $1 \mathrm{~h}$. The cells were then washed with $1 \mathrm{X}$ PBS and mounted with 4',6-diamidino-2-phenylindole mounting solution on slides purchased from Vector Laboratories, Inc. (Burlingame, CA, USA) and were designated for confocal image analysis. All confocal images were captured with a $\mathrm{x} 20$ oil objective (numerical aperture 3.5) lenses of Olympus Fluoview FV1000. FV10-ASW 3.1 viewer software (Olympus Corporation, Tokyo, Japan) was used to extract the images.

Statistical analysis. The obtained results are expressed as the mean \pm standard deviation of a minimum three replicates in independent experiments. The data were analyzed by one-way analysis of variance followed by Tukey's test for the comparison of multiple independent variables using GraphPad Prism v.5.0 for Windows (GraphPad Software, Inc., La Jolla, CA, USA). $\mathrm{P}<0.05$ was considered to indicate a statistically significant difference.

\section{Results}

Quantification and characterization of terpenes. Steam distillation of $C$. obtusa leaves produced a light yellow-colored oil with a yield of $1.59 \%$ (w/w) based on green leaf. The GC/MS analyzed peaks revealed $>24$ components in the total ion chromatogram, as shown in Fig. 1. A total of 23 compounds (Table I) were identified from the leaf oil of C.obtusa. Among the leaf oil compounds, monoterpenes and oxygenated monoterpenes were predominant $(59.23 \%)$, followed by sesquiterpenes and oxygenated sesquiterpenes $(39.65 \%)$. Among the monoterpenes and oxygenated monoterpenes, sabinene (10.42\%) and $\alpha$-terpinyl acetate $(18.89 \%)$ were the major compounds, 
Table I. Chemical composition of the essential oil obtained from Chamaecyparis obtusa leaf.

\begin{tabular}{|c|c|c|c|c|c|c|c|c|}
\hline Peak no. & $\mathrm{RT}(\min )$ & Compound & $\mathrm{M}^{+}$ & Formula & Area $(\%)$ & $\mathrm{RI}^{\mathrm{a}}$ & $\mathrm{RI}^{\mathrm{b}}$ & Type \\
\hline 1 & 11.860 & Thujene & 136 & $\mathrm{C}_{10} \mathrm{H}_{16}$ & 0.54 & 921 & 920 & M \\
\hline 2 & 12.150 & $\alpha$-Pinene & 136 & $\mathrm{C}_{10} \mathrm{H}_{16}$ & 1.41 & 930 & 939 & M \\
\hline 3 & 14.380 & Sabinene & 136 & $\mathrm{C}_{10} \mathrm{H}_{16}$ & 10.42 & 971 & 976 & M \\
\hline 4 & 15.490 & Myrcene & 136 & $\mathrm{C}_{10} \mathrm{H}_{16}$ & 4.68 & 991 & 991 & M \\
\hline 5 & 16.730 & 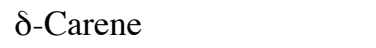 & 136 & $\mathrm{C}_{10} \mathrm{H}_{16}$ & 1.38 & 1,015 & 1,011 & M \\
\hline 6 & 17.405 & Limonene & 136 & $\mathrm{C}_{10} \mathrm{H}_{16}$ & 5.39 & 1,026 & 1,031 & M \\
\hline 7 & 19.090 & $\gamma$-Terpinene & 136 & $\mathrm{C}_{10} \mathrm{H}_{16}$ & 4.13 & 1,058 & 1,062 & M \\
\hline 8 & 20.650 & Terpinolene & 136 & $\mathrm{C}_{10} \mathrm{H}_{16}$ & 1.19 & 1,087 & 1,088 & M \\
\hline 9 & 25.315 & Terpinen-4-ol & 154 & $\mathrm{C}_{10} \mathrm{H}_{18} \mathrm{O}$ & 4.78 & 1,176 & 1,177 & M \\
\hline 10 & 26.000 & $\alpha$-Terpineol & 154 & $\mathrm{C}_{10} \mathrm{H}_{18} \mathrm{O}$ & 0.90 & 1,189 & 1,195 & M \\
\hline 11 & 30.750 & Bornyl acetate & 196 & $\mathrm{C}_{12} \mathrm{H}_{20} \mathrm{O}_{2}$ & 5.52 & 1,286 & 1,289 & M \\
\hline 12 & 33.820 & $\alpha$-Terpinyl acetate & 196 & $\mathrm{C}_{12} \mathrm{H}_{2} \mathrm{OO}_{2}$ & 18.89 & 1,351 & 1,352 & M \\
\hline 13 & 37.360 & Thujopsene (widdrene) & 204 & $\mathrm{C}_{15} \mathrm{H}_{24}$ & 1.55 & 1,431 & 1,431 & $\mathrm{~S}$ \\
\hline 14 & 38.030 & cis-Muurola-3,5-diene & 204 & $\mathrm{C}_{15} \mathrm{H}_{24}$ & 0.73 & 1,447 & 1,446 & $\mathrm{~S}$ \\
\hline 15 & 38.770 & $\begin{array}{l}1,2,3,5,6,7,8,8 \mathrm{a}- \\
\text { Octahydro-1-methyl-6- } \\
\text { methylene-4-(1- } \\
\text { methylethyl) naphthalene }\end{array}$ & 204 & $\mathrm{C}_{15} \mathrm{H}_{24}$ & 1.54 & 1,464 & 1,464 & $S$ \\
\hline 16 & 39.560 & Germacrene-D & 204 & $\mathrm{C}_{15} \mathrm{H}_{24}$ & 0.78 & 1,482 & 1,480 & $\mathrm{~S}$ \\
\hline 17 & 40.330 & Unknown & 204 & $\mathrm{C}_{15} \mathrm{H}_{24}$ & 1.19 & 1,500 & - & $\mathrm{S}$ \\
\hline 18 & 41.370 & 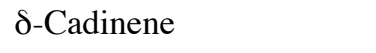 & 204 & $\mathrm{C}_{15} \mathrm{H}_{24}$ & 0.67 & 1,507 & 1,524 & $\mathrm{~S}$ \\
\hline 19 & 42.525 & Elemol & 222 & $\mathrm{C}_{15} \mathrm{H}_{26} \mathrm{O}$ & 17.45 & 1,552 & 1,550 & $\mathrm{~S}$ \\
\hline 20 & 44.550 & Cedrol & 222 & $\mathrm{C}_{15} \mathrm{H}_{26} \mathrm{O}$ & 0.81 & 1,603 & 1,596 & $\mathrm{~S}$ \\
\hline 21 & 45.805 & $\gamma$-Eudesmol & 222 & $\mathrm{C}_{15} \mathrm{H}_{26} \mathrm{O}$ & 6.62 & 1,634 & 1,626 & $\mathrm{~S}$ \\
\hline 22 & 46.520 & $\beta$-Eudesmol & 222 & $\mathrm{C}_{15} \mathrm{H}_{26} \mathrm{O}$ & 3.84 & 1,653 & 1,651 & $\mathrm{~S}$ \\
\hline 23 & 46.640 & $\alpha$-Eudesmol & 222 & $\mathrm{C}_{15} \mathrm{H}_{26} \mathrm{O}$ & 4.47 & 1,656 & - & $\mathrm{S}$ \\
\hline 24 & 56.525 & Beyerene (hibaene) & 272 & $\mathrm{C}_{20} \mathrm{H}_{32}$ & 1.11 & 1,930 & 1,995 & $\mathrm{D}$ \\
\hline Total & & & & & 99.99 & & & \\
\hline
\end{tabular}

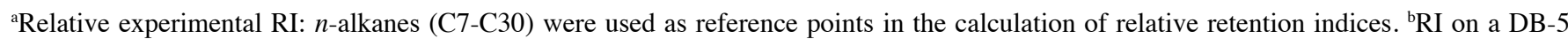
column with reference to $n$-alkanes. Monoterpenes (29.14\%) and oxygenated monoterpenes (30.09\%), sesquiterpenes $(6.46 \%)$ and oxygenated sesquiterpenes (33.19\%), diterpenes (1.11\%). RT, retention time; RI, retention index; M, monoterpenes; S, sesquiterpenes; D, diterpenes.

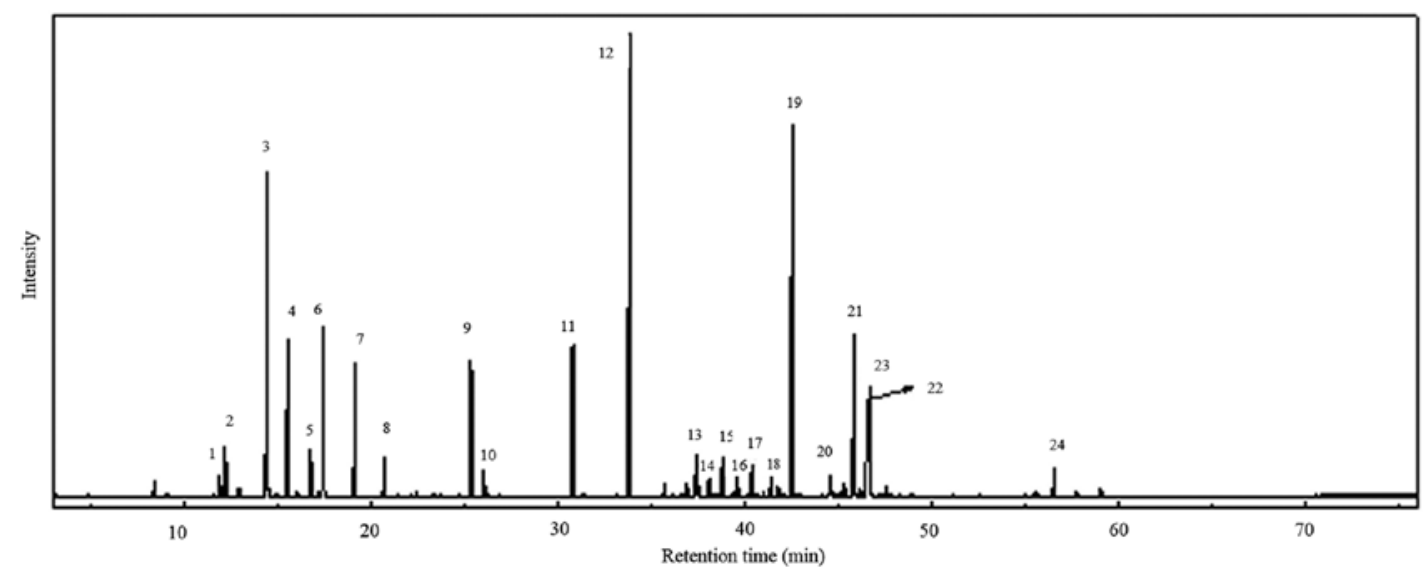

Figure 1. Total ion chromatogram of essential oil extracted from hinoki cypress (Chamaecyparis obtusa) leaf. A total of 24 component peaks were observed. The peaks were categorized as 12 monoterpenes; 11 sesquiterpenes and 1 diterpene.

with oxygenated sesquiterpenes carrying elemol (17.45\%) as the main compound including sub major compounds listed in Table II. The compounds were identified with reference to previous studies (19-22). 
Table II. Main major compounds of essential oil from hinoki cypress leaf analyzed by GC-MS.

\begin{tabular}{llcrrl}
\hline Compound & Formula & Area (\%) & $\mathrm{RI}^{\mathrm{a}}$ & $\mathrm{RI}^{\mathrm{b}}$ & \multicolumn{1}{c}{ Type } \\
\hline Sabinene & $\mathrm{C}_{10} \mathrm{H}_{16}$ & 10.42 & 971 & 976 & Monoterpene \\
$\alpha$-Terpinyl acetate & $\mathrm{C}_{12} \mathrm{H}_{20} \mathrm{O}_{2}$ & 18.89 & 1,351 & 1,352 & Oxygenated monoterpene \\
Elemol & $\mathrm{C}_{15} \mathrm{H}_{26} \mathrm{O}$ & 17.45 & 1,552 & 1,550 & Oxygenated sesquiterpene \\
Myrcene & $\mathrm{C}_{10} \mathrm{H}_{16}$ & 4.68 & 991 & 991 & Monoterpene \\
Limonene & $\mathrm{C}_{10} \mathrm{H}_{16}$ & 5.39 & 1,026 & 1,031 & Monoterpene \\
$\gamma$-Terpinene & $\mathrm{C}_{10} \mathrm{H}_{16}$ & 4.13 & 1,058 & 1,062 & Monoterpene \\
Terpinen-4-ol & $\mathrm{C}_{10} \mathrm{H}_{18} \mathrm{O}$ & 4.78 & 1,176 & 1,177 & Oxygenated monoterpene \\
Bornyl acetate & $\mathrm{C}_{12} \mathrm{H}_{20} \mathrm{O}_{2}$ & 5.52 & 1,286 & 1,289 & Oxygenated monoterpene \\
$\gamma$-Eudesmol & $\mathrm{C}_{15} \mathrm{H}_{26} \mathrm{O}$ & 6.62 & 1,634 & 1,626 & Oxygenated sesquiterpene \\
$\beta$-Eudesmol & $\mathrm{C}_{15} \mathrm{H}_{26} \mathrm{O}$ & 3.84 & 1,653 & 1,651 & Oxygenated sesquiterpene \\
$\alpha$-Eudesmol & $\mathrm{C}_{15} \mathrm{H}_{26} \mathrm{O}$ & 4.47 & 1,656 & - & Oxygenated sesquiterpene \\
Total & & 86.19 & & &
\end{tabular}

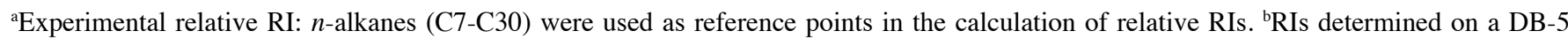
column with reference to $n$-alkanes. RI, retention index.
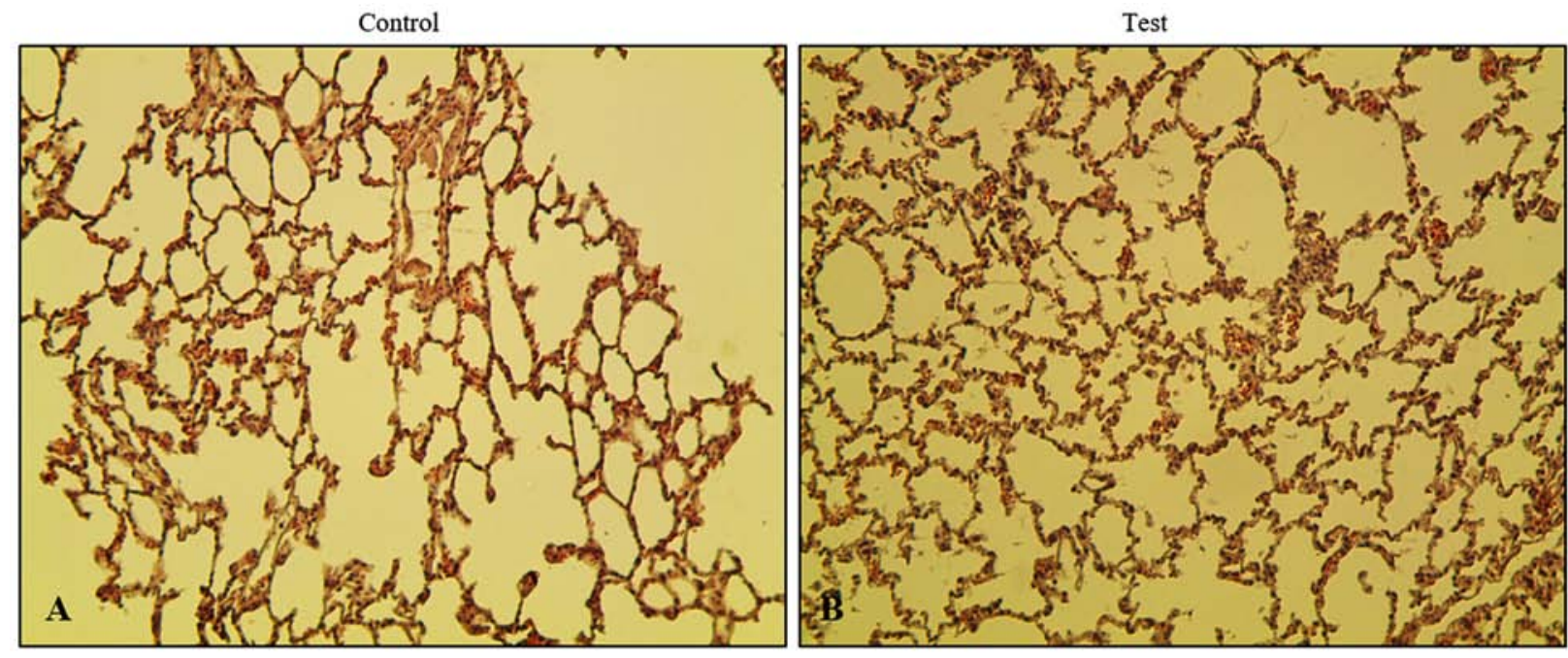

Figure 2. Histopathological changes in lung tissue following essential oil inhalation. Hematoxylin and eosin staining of tissues (B) in rats exposed to essential oil phytoncide inhalation $\left(100 \mathrm{~kg} / \mathrm{cm}^{3}\right.$ ) or (A) normal (control) Sprague-Dawley rats over 4 weeks of treatment were observed under a microscope (magnification, $\mathrm{x} 400$ ).

Phytoncide essential oil enhances lung alveolar capacity. To evaluate the effect of phytoncide essential oil on rats via olfactory stimulation, the lungs were removed followed by subsequent fixing and staining. In order to investigate the histopathological changes in the phytoncide essential oil-administered or inhalation model, hematoxylin and eosin staining was performed. It was observed that xenograft lung tissues in the test group showed more alveoli in the lungs than the control group (Fig. 2). No significant difference between the control and test group was found when comparing the thickness of the interstitial space layer, with the exception ofin the nucleus. There was no exudate found inside the alveolar layer. An increase of spontaneous volume and a decrease in alveolar dead space were observed. In addition, no toxic interstitial pneumonia or inflammation was observed in the test group rats, confirming that there was no microbial infection in the lungs. This observation indicates that the airway inhalation of phytoncide essential oil by Sprague-Dawley rats did not cause any microbial infection or inflammation over the course duration of phytoncide administration. Instead, there was an enhancement in the breathing capacity of the lungs.

Effect of phytoncide essential oil on cell viability and LPS stimulation on WI38 fibroblast cells. The effect of phytoncide from hinoki leaf extracted essential oil on the viability of WI38 cells was measured at doses ranging between 1 and $50 \mu \mathrm{g} / \mathrm{ml}$ and of LPS concentrations ranging between 1 and $10 \mu \mathrm{g} / \mathrm{ml}$ using an MTT assay following incubation of the cells for $24 \mathrm{~h}$ (Fig. 3A and B). It was observed that cell viability was not affected until a $10 \mu \mathrm{g} / \mathrm{ml}$ dose of phytoncide essential oil and significant cell growth inhibition (47\%) was observed at the $50 \mu \mathrm{g} / \mathrm{ml}$ dose. LPS stimulation led to changes in cell morphology at 5 and $10 \mu \mathrm{g} / \mathrm{ml}$ concentrations, compared 


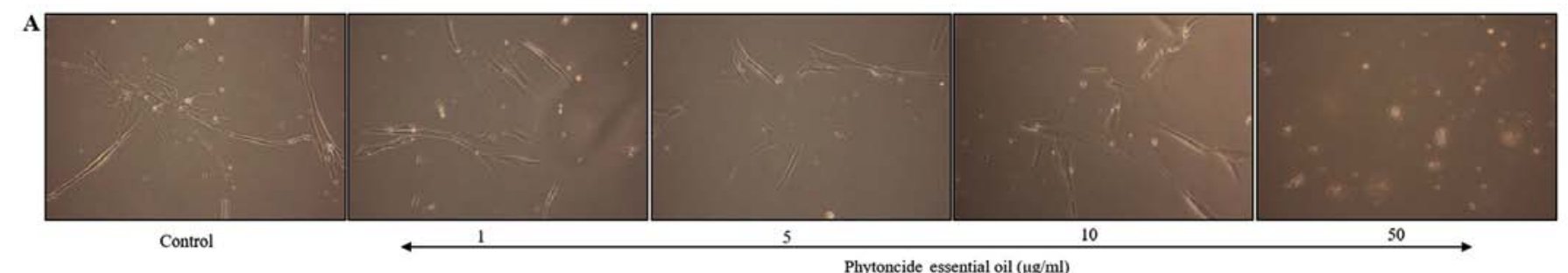

B

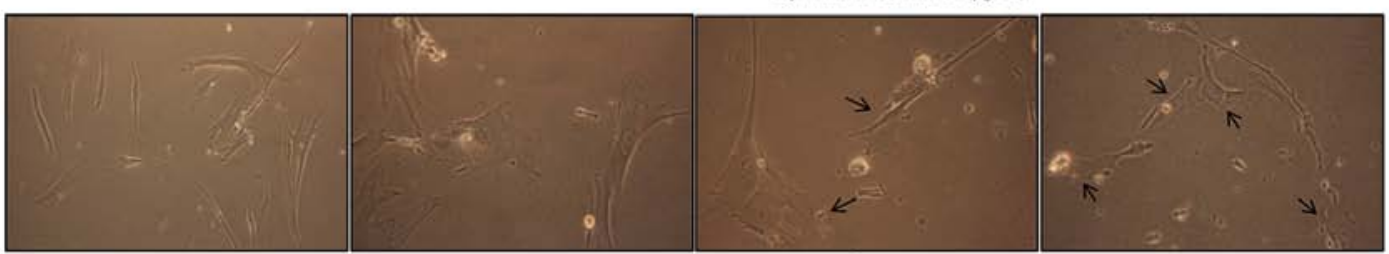

Control
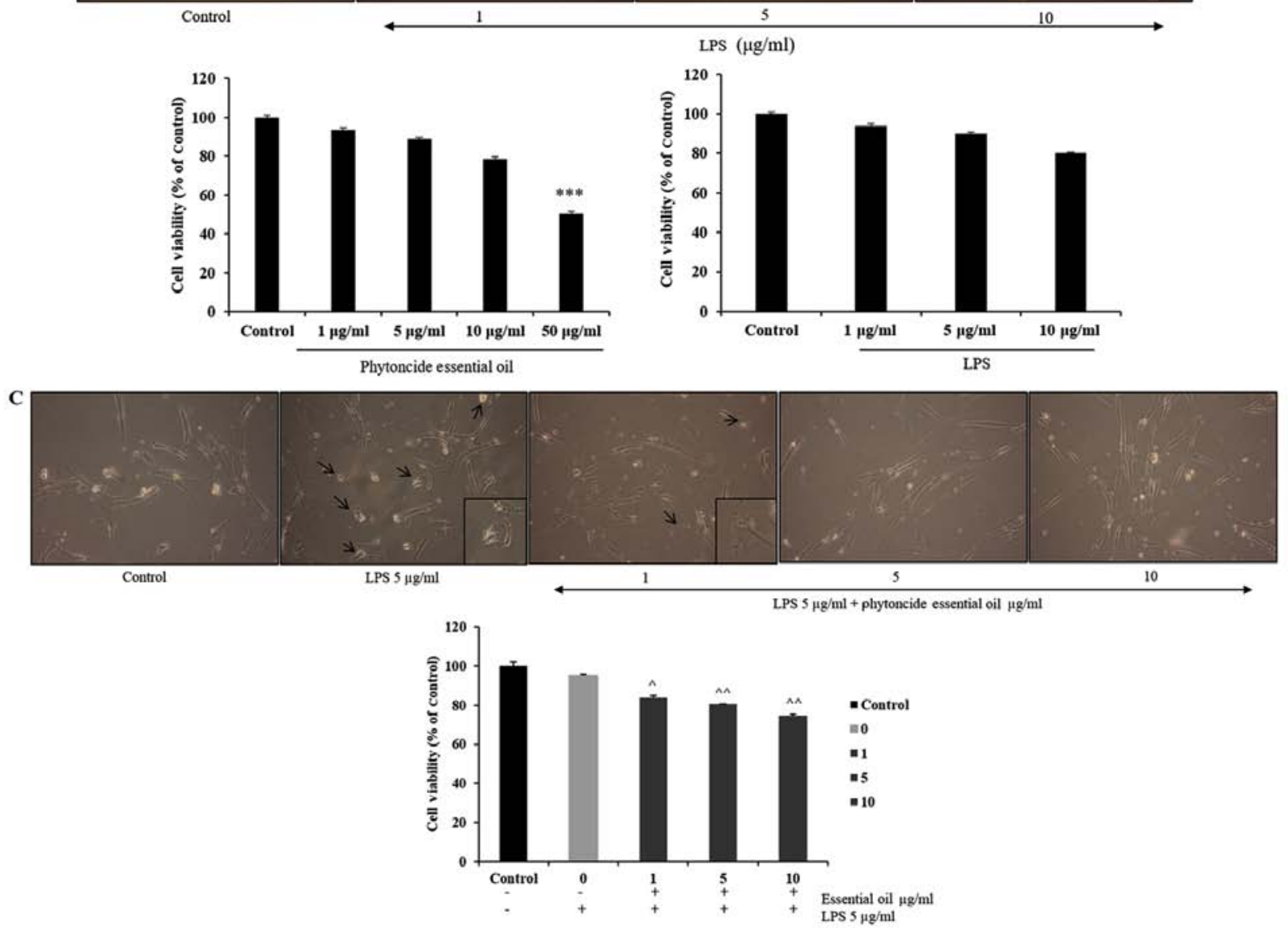

Figure 3. Cell compatibility and anti-stimulatory effect of essential oil on LPS-induced WI38 fibroblast cell inflammation. (A) Morphological observation of WI38 fibroblast cells treated with various concentrations $(1-50 \mu \mathrm{g} / \mathrm{ml})$ of essential oil on cell compatibility. (B) Morphological observations of WI38 fibroblast cells show the inflammatory effects of LPS stimulation (1-10 $\mu \mathrm{g} / \mathrm{ml})$ compared with untreated cells. (C) Morphological observation of inflammation reduction in the $1 \mathrm{~h}$ pre-essential oil treated group in $5 \mu \mathrm{g} / \mathrm{ml}$ LPS-stimulated WI38 cells at $24 \mathrm{~h}$. Cell viability observations showed that essential oil treatment in the LPS-stimulated groups significantly suppressed inflammation compared with that in the positive control or LPS stimulation-induced cells (magnification, x10). Black arrows indicate the morphological changes in fibroblast cells induced by LPS stimulation. Data represented as the mean \pm standard deviation of three replicate independent experiments. ${ }^{* * *} \mathrm{P}<0.01$, compared with the subsequent control group; ${ }^{\wedge} \mathrm{P}<0.05$ and ${ }^{\wedge} \mathrm{P}<0.01$, compared with the LPS-stimulated group. LPS, lipopolysaccharide.

with the subsequent control. The selected concentrations of phytoncide essential oil were $1-10 \mu \mathrm{g} / \mathrm{ml}$ based on the cell compatibility comparing with control; the LPS stimulatory dose was selected as $5 \mu \mathrm{g} / \mathrm{ml}$ based on the morphological changes. It was observed that the normal fibroblast morphology of cells was altered, exhibiting swelling and pseudopodia formation in the LPS-stimulated cells. Furthermore, it was observed that pre-treatment with $1-10 \mu \mathrm{g} / \mathrm{ml}$ concentrations of phytoncide essential oil significantly reduced the stimulated swelling and pseudopodia formation induced by LPS in a dose-dependent manner (Fig. 3C). Therefore, these data indicate that the morphological observation of WI38 fibroblast cell inflammation by LPS can be suppressed by the terpenes of essential oil from C. obtusa leaf.

\section{LPS-induced expression of iNOS and COX-2 is inhibited by} phytoncide essential oil in WI38 fibroblast cells. In order to investigate the anti-inflammatory effect of phytoncide essential oil, western blot analysis was performed. The experimental results of the western blot analysis determined that 

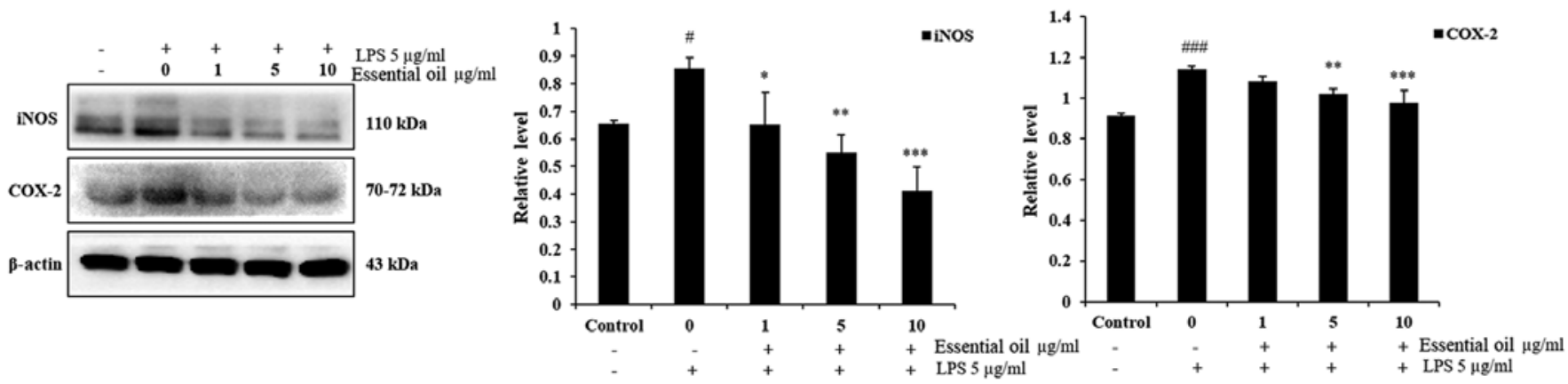

Figure 4. Suppression of iNOS and COX-2 in LPS-stimulated WI38 fibroblast cells by essential oil treatment. WI38 cells were pre-treated with 1-10 $\mu \mathrm{g} / \mathrm{ml}$ concentrations of phytoncide essential oil for $1 \mathrm{~h}$ followed by $5 \mu \mathrm{g} / \mathrm{ml}$ LPS treatment for $24 \mathrm{~h}$. The effect of phytoncide essential oil on the LPS-induced pro-inflammatory mediator protein expression of iNOS and COX-2 were observed by immuno-blotting. Densitometric analyses showed the suppressed expression of iNOS and COX-2 proteins compared with the LPS (positive control) group of WI38 cells. Data represented as the mean \pm standard deviation of three replicate independent experiments. ${ }^{*} \mathrm{P}<0.05,{ }^{* *} \mathrm{P}<0.01$ and ${ }^{* * *} \mathrm{P}<0.001$ compared with the positive control group; ${ }^{*} \mathrm{P}<0.05$ and ${ }^{\# \# \#} \mathrm{P}<0.01$, compared with the negative control (un-treated) group. $\beta$-actin was used as internal control. iNOS, inducible nitric oxide synthase; COX-2, cyclooxygenase-2; LPS, lipopolysaccharide.

$5 \mu \mathrm{g} / \mathrm{ml}$ LPS markedly increased the expression of iNOS and COX-2 at $24 \mathrm{~h}$ duration in the WI38 fibroblast cells compared with the untreated control group of WI38 cells. Pre-treatment of the WI38 cells with $1-10 \mu \mathrm{g} / \mathrm{ml}$ phytoncide essential oil for $1 \mathrm{~h}$ led to a significant decrease in the expression of iNOS in a dose-dependent manner compared with that in the LPS-stimulated cells at $24 \mathrm{~h}$. Furthermore, phytoncide essential oil significantly suppressed the production of COX-2 in the LPS-stimulated WI38 cells at 5 and $10 \mu \mathrm{g} / \mathrm{ml}$ doses. These data indicated that, the terpenes of essential oil from C. obtusa leaf inhibits LPS-stimulated protein secretion of iNOS and COX-2 in WI38 fibroblast cells (Fig. 4).

Phytoncide essential oil attenuates $N F-\kappa B$ activation. NF- $\kappa \mathrm{B}$ is activated at sites of inflammatory disease. To confirm the anti-inflammatory role of phytoncide essential oil in WI38 cells, the expression of inflammatory proteins were detected and evaluated. The phosphorylation of NF- $\mathrm{KB}$ or translocation of NF- $\mathrm{KB}$ to the nucleus of the WI38 inflamed cells were observed via immunofluorescence. The confocal imaging results indicated that the LPS-treated cells exhibited a marked increase of p-p65 in the nucleus, compared with the untreated or negative control cells. The co-treated groups showed complete suppression of the expression of p-p65 in the nucleus of WI38 cells pre-treated with 5 and $10 \mu \mathrm{g} / \mathrm{ml}$ phytoncide essential oil (Fig. 5A). Furthermore, the protein expression of the total form of p65 decreased in the LPS-stimulated group was significantly increased in the phytoncide essential oil co-treated groups, and NF- $\kappa \mathrm{B}$ inhibitor or inactivated I $\kappa$ B- $\alpha$ protein also decreased following LPS-stimulation and increased in the phytoncide essential oil pre-treated group in the total cell lysate (Fig. 5B). Therefore, these data indicated that treatment with essential oil from C.obtusa leaf containing terpenes inhibited the inflammation in WI38 fibroblast cells exposed to LPS stimulation by inhibiting the translocation of $\mathrm{NF}-\kappa \mathrm{B}$ from the cytosol leading to nuclear activation.

\section{Discussion}

Inflammation is a protective response to noxious stimuli that occurs unavoidably at a cost to normal tissue function, mainly depending on the type of cells and molecular media- tors involved, and are classified as acute vs. chronic and local vs. systemic (23). The characteristic features of several chronic inflammatory diseases are their persistence and predilection for certain sites. The prevalence of any disease is due to the lack of therapeutic targets which have no side effects during treatment. The mechanism underlying the development of inflammation and pathological pain in disease is associated with an increase in pro-inflammatory cytokines interleukin (IL)- 6 , IL-8, IL- $\beta$, tumor necrosis factor (TNF)- $\alpha$, chemokines, adhesion molecules, and matrix metalloproteinases, followed by a decrease in anti-inflammatory interleukin secretion, the production of COX-2 and iNOS and activation of the NF- $\mathrm{KB} /$ Rel transcription family pathways (24).

Natural products and the therapeutic strategies related to them are the foremost treatment methods in the development for a potent medicine with no adverse effects. Several reports on the anti-inflammatory effects of bioactive medicinal herbs have explained these: Ailanthus altissima in ovalbumin induced lung inflammation via the down-regulation of T helper 2(Th2) cytokines and eotaxin transcripts in bone marrow-derived mast cells (25); herb mixture PM014 attenuated lung inflammation in a murine model Balb/c mice against COPD (26); pomegranate extract attenuated cigarette smoking-induced inflammation in human alveolar cells (27), and curcumin-resveratrol combination led to anti-inflammatory and proapoptotic effects in the MRC-5 human lung fibroblast cell line (28).

Essential oils are complex volatile compounds, which have potential therapeutic activity that depends mainly on their types, including aldehydes, phenolics, terpenes, and other antimicrobial compounds (29). Essential oil mixed with mint, eucalyptus, spruce and frankincense compounds have exhibited curative effects against acute airway inflammation induced by air $\mathrm{PM}_{2.5}$ air pollutants in mice (30). Phytoncide or wood essential oil has been investigated for health beneficial activities, including enhancing the activity of NK cells by the induction of intracellular perforin, granzyme A, and granulysin in NK-92MI human cells (31). Hinoki cypress (C. obtusa) is a coniferous tree and predominant cypress species in Asia, found in Japan and South Korea, which contains volatile or essential oil in its leaves and twigs. The direct inhalation of essential oil or contact with cypress wood has been widely investigated for its physiological and psychological relaxation properties 


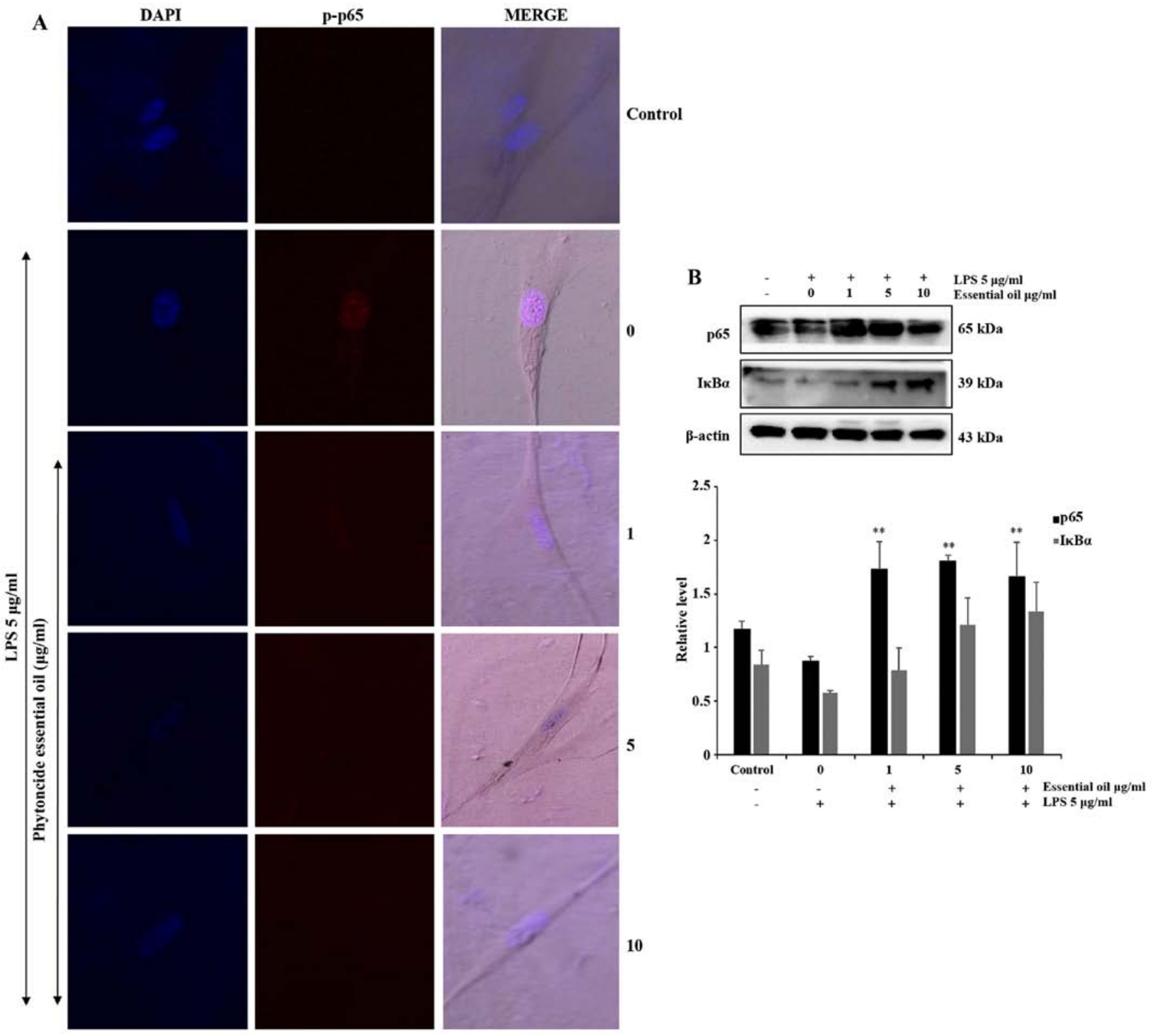

Figure 5. NF-кB inhibition by essential oil treatment of LPS-inflamed WI38 fibroblast cells. Representative images of cellular localization and immuno-blot analysis in WI38 cells. (A) Confocal images showed p-p65 or NF-kB translocation to the nucleus following LPS stimulation compared with untreated cells, whereas the phytoncide essential oil pre-treated group showed suppressed NF- $\mathrm{\kappa B}$ activation and reversion of its location to the cytosol (magnification, $\mathrm{x} 20$ ).

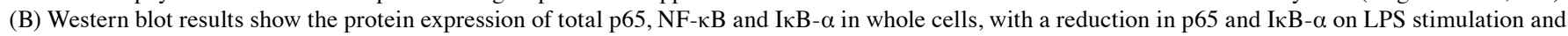
a subsequent increase in the phytoncide essential oil co-treated group of WI38 cells. Data represented as the mean \pm standard deviation of three replicate independent experiments. ${ }^{* *} \mathrm{P}<0.01$, compared with the LPS-stimulated group. $\beta$-actin was used as internal control. LPS, lipopolysaccharide; NF- $\mathrm{KB}$, nuclear factor $\kappa$-light-chain-enhancer of activated B cells; IкB, inhibitor of NF-кB; p-p65, phosphorylated p65.

without harmful effects on the body $(8,12,13,32)$. In vitro studies have shown that phytoncides decrease the capacity of LPS-induced inflammatory responses in MAC-T mammary alveolar epithelial cells (33) and in RAW 264.7 macrophage cells (18). Monoterpene $\beta$-thujaplicin of $C$. obtusa have been shown to inhibit inflammatory expression in RAW 264.7 cells and septic shock in mice (34); whereas $\alpha$-phellandrene monoterpene in Schinus molle L. essential oil exhibits enhanced NK cell activity in normal BALB/c mice (35). Similarly, in the present study, exposure to terpenes of essential oil at different concentrations led to the inhibition of LPS-induced inflammation in WI38 cells, and inhalation of the essential oil enhanced the capacity of lung alveoli in rats.
Inflammatory mediators, including eicosanoids, are biosynthesized by COX and lipoxygenase enzymes, in which the eicosanoid-generating enzyme, COX-2 has been found to be essential for the production of prostaglandins in inflammatory diseases $(25,36)$. The up-regulation of COX-2 leads to inflammatory cytokine release, which can further dictate the extent and type of inflammatory response from immune and non-immune cells. In chronic lung inflammation, pro-fibrotic and immuno-regulatory $\mathrm{Th} 2$ cytokines are important in disease exaggeration (2). The role of iNOS protein in the pathogenesis of allergen-induced airway inflammation and lung fibrosis further explains the function of this protein in defining the context of acute or chronic inflammatory response 


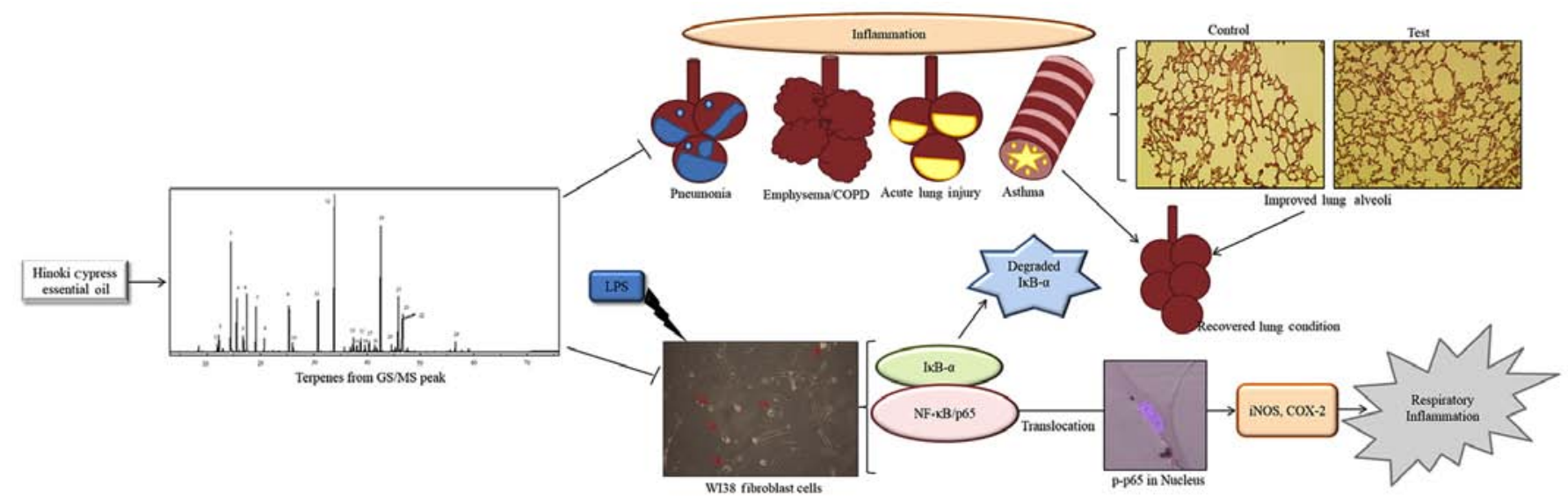

Figure 6. Schematic diagram showing the anti-inflammatory regulation by phytoncide essential oil on lung inflammation. LPS stimulated NF- $\mathrm{kB}$ and inflammatory mediator activation in WI38 cell inflammation. Phytoncide essential oil inhibited the LPS-induced inflammation in WI38 cells and enhanced the lung alveolar capacity in Sprague-Dawley rats, indicating its therapeutic potency for lung inflammatory diseases. LPS, lipopolysaccharide; NF-кB, nuclear factor

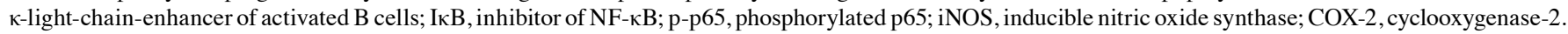

in disease exaggeration (1). Several studies have addressed the anti-inflammatory regulation by the inhibition of iNOS and COX-2 in injured, allergy-evoked or damaged tissue and cells, suggesting therapeutic targets for respiratory inflammatory disease $(1,25,37,38)$. Similarly, the present study showed that terpenes in essential oil inhibited the LPS-stimulated expression of iNOS and COX-2 inflammatory mediators in WI38 fibroblast cells.

The redox-sensitive transcription factor, $N F-\kappa B$, is an important participant in a broad spectrum of inflammatory networks that regulate cytokine activity in airway pathology (39). Prominent transcription factors in airway disease include NF- $\mathrm{NB}$, activator protein-1 (AP-1), glucocorticoid receptors and nuclear factor of activated $\mathrm{T}$ cells (40). Inflammatory target proteins, including MMP-9, intercellular adhesion molecule-1, vascular cell adhesion molecule-1, COX-2 and cytosolic phospholipase A2, are associated with airway and lung inflammation in response to various stimuli (41). Therapeutics that target the NF- $\kappa$ B family can inhibit its translocation during inflammation in a process termed trans-repression and can protect against the condition of pulmonary and airway obstruction-associated inflammation $(23,39)$. Several studies have described the therapeutic implications on lung diseases and its pathogenesis by inhibiting the NF- $\kappa$ B pathway through microRNA-194 in infantile pneumonia (42), and curcumin and resveratrol combination in MRC-5 cells for idiopathic pulmonary fibrosis (28). The suppression of $\mathrm{NF}-\kappa \mathrm{B}$ in inflammatory diseases by natural compounds derived from plants have been reported for inflammatory diseases by inhibiting its downstream targets viz., and inflammatory mediators iNOS, COX-2 and PGE2 (43-47). The utilization of natural compounds as a potential treatment method in inflammatory airway diseases, for reversion to the healthy condition of cells or tissues, is a prime target of investigation. Therefore, the present study supports that terpenes in essential oil from the C. obtusa leaf inhibits the translocation of NF- $\kappa \mathrm{B}$ in WI38 cells.

The present study sheds light on the anti-inflammatory mechanism of terpenes in phytoncide essential oil from the Korean $C$. obtusa leaf by inhibiting the inflammatory mediators iNOS and COX-2 and potent transcription factor $\mathrm{NF}-\kappa \mathrm{B}$ in order to protect the lung from severe inflammatory diseases (Fig 6). Therefore, these findings suggest that terpene compounds in essential oil of hinoki cypress can be used as a safe therapeutic agent for the treatment of respiratory inflammation and improvement of respiration capacity. However, further investigations are required to provide further insight into the details of its molecular mechanism.

\section{Acknowledgements}

Not applicable.

\section{Funding}

This study was supported by the National Research Foundation of Korea funded by MSIT (grant nos. 2012M3A9B8019303 and 2017R1A2B4003974).

\section{Availability of data and materials}

All data generated or analyzed during this study are included in this published article.

\section{Authors' contributions}

SR, SPM, SJL and GSK designed the study protocol. SR performed the in vitro experiments, analyzed statistical data, wrote and revised the manuscript. SR, SMK, HJL, VVGS, SEH and EHK performed the in vivo experiment. SJL and JDH performed the in vivo rat tissue experiment. SMK performed the experimental analysis and manuscript revision. SPM performed the GC/MS analysis and compound identification. GSK provided advise for the experimental analysis.

\section{Ethics approval and consent to participate}

The present study was performed following the standard animal science guidelines reviewed and approved by the Ethics 
Committee of Gyeongnam Biological Resource Research Center (Gyeongnam, Korea).

\section{Patient consent for publication}

Not applicable.

\section{Competing interests}

The authors declare that they have no competing interests.

\section{References}

1. Naura AS, Zerfaoui M, Kim H, Abd Elmageed ZY, Rodriguez PC, Hans CP, Ju J, Errami Y, Park J, Ochoa AC, et al: Requirement for inducible nitric oxide synthase in chronic allergen exposure-induced pulmonary fibrosis but not inflammation. J Immunol 185: 3076-3085, 2010.

2. Moldoveanu B, Otmishi P, Jani P, Walker J, Sarmiento X, Guardiola J, Saad M and Yu J: Inflammatory mechanisms in the lung. J Inflamm Res 2: 1-11, 2009.

3. Stellari F, Bergamini G, Ruscitti F, Sandri A, Ravanetti F, Donofrio G, Boschi F, Villetti G, Sorio C, Assael BM, et al: In vivo monitoring of lung inflammation in CFTR-deficient mice. J Transl Med 14: 226, 2016.

4. Eutamene H, Theodorou V, Schmidlin F, Tondereau V, GarciaVillar R, Salvador-Cartier C, Chovet M, Bertrand C and Bueno L: LPS-induced lung inflammation is linked to increased epithelial permeability: Role of MLCK. Eur Respir J 25: 789-796, 2005.

5. Van Linthout S, Miteva K and Tschöpe C: Crosstalk between fibroblasts and inflammatory cells. Cardiovasc Res 102: 258-269, 2014.

6. Vancheri C, Mastruzzo C, Tomaselli V, Sortino MA, D'Amico L, Bellistrí G, Pistorio MP, Salinaro ET, Palermo F, Mistretta A, et al: Normal human lung fibroblasts differently modulate interleukin-10 and interleukin-12 production by monocytes: Implications for an altered immune response in pulmonary chronic inflammation. Am J Respir Cell Mol Biol 25: 592-599, 2001.

7. Flavell SJ, Hou TZ, Lax S, Filer AD, Salmon M and Buckley CD: Fibroblasts as novel therapeutic targets in chronic inflammation. Br J Pharmacol 153 (Suppl 1): S241-S246, 2008.

8. Ikei H, Song C and Miyazaki Y: Physiological effect of olfactory stimulation by Hinoki cypress (Chamaecyparis obtusa) leaf oil. J Physiol Anthropol 34: 44, 2015.

9. Lee SH, Do HS and Min KJ: Effects of essential oil from Hinoki cypress, Chamaecyparis obtusa, on physiology and behavior of flies. PLoS One 10: e0143450, 2015.

10. Abe T, Hisama M, Tanimoto S, Shibayama H, Mihara Y and Nomura M: Antioxidant effects and antimicrobial activites of phytoncide. Biocontrol Sci 13: 23-27, 2008.

11. Zhang S, Jung JH, Kim HS, Kim BY and Kim IH: Influences of phytoncide supplementation on growth performance, nutrient digestibility, blood profiles, diarrhea scores and fecal microflora shedding in weaning pigs. Asian-Australas J Anim Sci 25: 1309-1315, 2012.

12. Li Q: Effect of forest bathing trips on human immune function. Environ Health Prev Med 15: 9-17, 2010.

13. Li Q, Kobayashi M, Wakayama Y, Inagaki H, Katsumata M, Hirata Y, Hirata K, Shimizu T, Kawada T, Park BJ, et al: Effect of phytoncide from trees on human natural killer cell function. Int J Immunopathol Pharmacol 22: 951-959, 2009.

14. Sobral MV, Xavier AL, Lima TC and de Sousa DP: Antitumor activity of monoterpenes found in essential oils. ScientificWorldJournal 2014, e953451, 2014.

15. Juergens UR: Anti-inflammatory properties of the monoterpene 1.8-cineole: Current evidence for co-medication in inflammatory airway diseases. Drug Res (Stuttg) 64: 638-646, 2014.

16. Guerreiro M, Mernak M, Santana F, Pinheiro N, Ramanholo BS, Capello T, Lolanda T, Martins M, Lago J and Prado C: Essential oils reduced lung inflammation in a model of acute lung injury. Eur Respir J 44: 3925, 2014.

17. Games E, Guerreiro M, Santana FR, Pinheiro NM, de Oliveira EA, Lopes FD, Olivo CR, Tibério IF, Martins MA, Lago JH, et al: Structurally related monoterpenes p-Cymene, carvacrol and thymol isolated from essential oil from leaves of Lippia sidoides Cham. (Verbenaceae) protect mice against elastase-induced emphysema. Molecules 21: E1390, 2016.
18. Park Y, Yoo SA, Kim WU, Cho CS, Woo JM and Yoon CH: Anti-inflammatory effects of essential oils extracted from Chamaecyparis obtusa on murine models of inflammation and RAW 264.7 cells. Mol Med Rep 13: 3335-3341, 2016.

19. Kuiate JR, Bessière JM, Zollo PH and Kuate SP: Chemical composition and antidermatophytic properties of volatile fractions of hexanic extract from leaves of Cupressus lusitanica Mill. from Cameroon. J Ethnopharmacol 103: 160-165, 2006.

20. Su YC and Ho CL: Composition and two activities of the leaf essential oil of Litsea acuminata (Blume) Kurata from Taiwan. Rec Nat Prod 7: 27-34, 2013.

21. Wang SY, Wang YS, Tseng YH, Lin CT and Liu CP: Analysis of fragrance compositions of precious coniferous woods grown in Taiwan. Holzforschung 60: 528-532, 2006.

22. Xu Brittany M, Baker George L, Sarnoski Paul J and GoodrichSchneide Renée M: A comparison of the volatile components of cold pressed Hamlin and Valencia (Citrus sinensis (L.) Osbeck) orange oils affected by Huanglongbing. J Food Qual 2017: 6793986, 2017.

23. Okin D and Medzhitov R: Evolution of inflammatory diseases. Curr Biol 22: R733-R740, 2012.

24. Tak PP and Firestein GS: NF-kappaB: A key role in inflammatory diseases. J Clin Invest 107: 7-11, 2001.

25. Jin MH, Yook J, Lee E, Lin CX, Quan Z, Son KH, Bae KH, Kim HP, Kang SS and Chang HW: Anti-inflammatory activity of Ailanthus altissima in ovalbumin-induced lung inflammation. Biol Pharm Bull 29: 884-888, 2006.

26. Lee H, Kim Y, Kim HJ, Park S, Jang YP, Jung S, Jung $H$ and Bae H: Herbal formula, PM014, attenuates lung inflammation in a murine model of chronic obstructive pulmonary disease. Evid Based Complement Alternat Med 2012: 769830, 2012.

27. Husari A, Hashem Y, Bitar H, Dbaibo G, Zaatari G and El Sabban M: Antioxidant activity of pomegranate juice reduces emphysematous changes and injury secondary to cigarette smoke in an animal model and human alveolar cells. Int J Chron Obstruct Pulmon Dis 11: 227-237, 2016.

28. Kloesch B, Dietersdorfer E, Loebsch S and Steiner G: Anti-inflammatory and pro-apoptotic effects of curcumin and resveratrol on the human lung fibroblast cell line MRC-5. Altern Integr Med 3: 174, 2014.

29. Swamy MK, Akhtar MS and Sinniah UR: Antimicrobial properties of plant essential oils against human pathogens and their mode of action: An updated review. Evid Based Complement Alternat Med 2016: 3012462, 2016.

30. Wang H, Song L, Ju W, Wang X, Dong L, Zhang Y, Ya P, Yang C and Li F: The acute airway inflammation induced by PM2.5 exposure and the treatment of essential oils in Balb/c mice. Sci Rep 7: 44256, 2017.

31. Li Q, Nakadai A, Matsushima H, Miyazaki Y, Krensky AM, Kawada T and Morimoto K: Phytoncides (wood essential oils) induce human natural killer cell activity. Immunopharmacol Immunotoxicol 28: 319-333, 2006.

32. Ikei H, Song $\mathrm{C}$ and Miyazaki Y: Physiological effects of touching hinoki cypress (Chamaecyparis obtusa). J. Wood Sci 64: 226-236, 2018.

33. Kang S, Lee JS, Lee HC, Petriello MC, Kim BY, Do JT, Lim DS, Lee HG and Han SG: Phytoncide extracted from pinecone decreases LPS-induced inflammatory responses in bovine mammary epithelial cells. J Microbiol Biotechnol 26: 579-587, 2016.

34. Shih MF, Chen LY, Tsai PJ and Cherng JY: In vitro and in vivo therapeutics of $\beta$-thujaplicin on LPS-induced inflammation in macrophages and septic shock in mice. Int J Immunopathol Pharmacol 25: 39-48, 2012.

35. Lin JJ, Lin JH, Hsu SC, Weng SW, Huang YP, Tang NY, Lin JG and Chung JG: Alpha-phellandrene promotes immune responses in normal mice through enhancing macrophage phagocytosis and natural killer cell activities. In Vivo 27: 809-814, 2013.

36. Lanas A, Haggerty P and Hirschowitz BI: In vitro studies of anti-inflammatory agents and prostaglandine 2 effects on stimulated normal human fibroblast cultures. Inflammopharmacology 2: 377-387, 1994.

37. Seo HR, Choi MJ, Choi JM, Ko JC, Ko JY and Cho EJ: Malvidin protects WI-38 human fibroblast cells against stress-induced premature senescence. J Cancer Prev 21: 32-40, 2016.

38. Thangavel J, Samanta S, Rajasingh S, Barani B, Xuan YT, Dawn B and Rajasingh J: Epigenetic modifiers reduce inflammation and modulate macrophage phenotype during endotoxemia-induced acute lung injury. J Cell Sci 128: 3094-3105, 2015.

39. Schuliga M: NF-kappaB signaling in chronic inflammatory airway disease. Biomolecules 5: 1266-1283, 2015. 
40. Barnes PJ: Transcription factors in airway diseases. Lab Invest 86: 867-872, 2006.

41. Lee IT and Yang CM: Inflammatory signalings involved in airway and pulmonary diseases. Mediators Inflamm 2013: 791231, 2013.

42. Xie F, Yang L, Han L and Yue B: MicroRNA-194 regulates lipopolysaccharide-induced cell viability by inactivation of nuclear factor- $\kappa$ B pathway. Cell Physiol Biochem 43: 2470-2478, 2017.

43. de Cassia da Silveira E Sa R, Andrade LN, Dos Reis Barreto de Oliveira R, de Sousa DP: A review on anti-inflammatory activity of phenylpropanoids found in essential oils. Molecules 19: 1459-1480, 2014.

44. Kim KN, Ko YJ, Yang HM, Ham YM, Roh SW, Jeon YJ, Ahn G, Kang MC, Yoon WJ, Kim D, et al: Anti-inflammatory effect of essential oil and its constituents from fingered citron (Citrus medica L. var. sarcodactylis) through blocking JNK, ERK and NF- $\mathrm{KB}$ signaling pathways in LPS-activated RAW 264.7 cells. Food Chem Toxicol 57: 126-131, 2013.

45. Chiang YM, Lo CP, Chen YP, Wang SY, Yang NS, Kuo YH and Shyur LF: Ethyl caffeate suppresses NF-kappaB activation and its downstream inflammatory mediators, iNOS, COX-2, and PGE2 in vitro or in mouse skin. Br J Pharmacol 146: 352-363, 2005.
46. Wei J, Zhang X, Bi Y, Miao R, Zhang Z and Su H: Antiinflammatory effects of cumin essential oil by blocking JNK, ERK, and NF- $\kappa \mathrm{B}$ signaling pathways in LPS-stimulated RAW 264.7 cells. Evid Based Complement Alternat Med 2015: 474509, 2015.

47. Raha S, Lee HJ, Yumnam S, Hong GE, Venkatarame Gowda Saralamma V, Ha YL, Kim JO, Kim YS, Heo JD, Lee SJ, et al: Vitamin D2 suppresses amyloid- $\beta$ 25-35 induced microglial activation in BV2 cells by blocking the NF- $\kappa \mathrm{B}$ inflammatory signaling pathway. Life Sci 161: 37-44, 2016.

This work is licensed under a Creative Commons Attribution-NonCommercial-NoDerivatives 4.0 International (CC BY-NC-ND 4.0) License. 